\title{
Investigation of the Performance of V-cut Turbines for Stirring Shear-thinning Fluids in a Cylindrical Vessel
}

\author{
Houari Ameur ${ }^{*}$ \\ 1 Department of Technology, University Centre of Naama - Salhi Ahmed, P. O. Box 66, Naama 45000, Algeria \\ * Corresponding author, e-mail: ameur@cuniv-naama.dz
}

Received: 26 October 2018, Accepted: 04 May 2020, Published online: 16 July 2020

\begin{abstract}
The impeller design is the most crucial parameter to enhance the performance of stirred tanks. The cut in the impeller blade is a new technique to save the energy of impellers in mixing vessels without increasing the mixing time or reducing the product quality. In this paper, the new technique of cut is applied for a disc turbine rotating in an unbaffled cylindrical tank. Effects of the V-cut shape are highlighted. Non-Newtonian shear-thinning fluids are considered for the three flow regimes (laminar, transient, and turbulent). Effects of the number of blades on the flow patterns, pumping rate $(\mathrm{Nq})$ and power consumption $(\mathrm{Np})$ are explored. From the obtained results, a recirculation loop of flow is observed at the tip of each blade for impellers with less than three blades. These recirculation loops disappear with the increased number of blades. Under laminar flow conditions, the obtained results also revealed a decrease in power consumption and an increase in the discharge flow rate with the rise of Reynolds number. However, almost any changes were observed for these parameters ( $N p$ and $N q$ ) under turbulent flow conditions.
\end{abstract}

Keywords

V-cut impeller, stirred tank, flow patterns, pumping rate, power consumption

\section{Introduction}

The mechanical agitation in cylindrical tanks is a fundamental operation in many industries to achieve various processes, such as chemical reaction, preparation of ingredients, and gas dispersion into a liquid for mass transfer or to form foams, etc.

The mechanical stirring of complex shear-thinning fluids is characterized by the formation of a well-stirred region around the impeller with a dead zone elsewhere [1]. The chemical engineers should reduce or eliminate these stagnant zones since they are characterized by poor mixing and poor heat and mass transfer. As an example, low product quality may be resulted by the high gradients in temperature and $\mathrm{pH}$, which are yielded by the poor mixing. The appropriate design of stirrers may allow the good mixing quality, as confirmed by many authors for the agitation of shear-thinning fluids [2-5].

The energy consumption is another important parameter to be considered in stirred tanks. For Rushton turbines, the power input may be reduced by decreasing the blade attack angle from $90^{\circ}$ to $45^{\circ}$ [6]. Beloudane et al. [7] designed a converging hollow blade to enhance the hydrodynamic characteristics and reduce the power consumption of radial impellers. Foukrach and Ameur [8] compared the efficiency of the curved bladed turbine and that of the standard Rushton turbine. They found that the best axial circulation of fluid is provided by the impeller with flat blades. The increased height of curved blades may generate a stronger tangential flow and enhance the axial movement of fluid particles, as reported by these authors. Other researchers were interested in the effect of vessel shape and some impeller geometrical parameters on the power consumption for stirring viscous fluids [9-11].

Rao and Sivashanmugam [12] suggested a new technique to reduce energy consumption, which is the introduction of a cut in the blade. In a recent study, Ameur [13] confirmed the efficiency of the cut technique for stirring yield stress fluids. In other studies [14, 15], some modifications have been introduced in curved-bladed impeller (cuts with different lengths and at different positions in the blade), and a significant decrease in power requirements was obtained.

In this paper, the performance of modified radial turbines is investigation. The new modification concerns 
the introduction of $\mathrm{V}$-cut in each blade of the impeller. The case of non-Newtonian shear-thinning fluids is explored. The impeller rotational speed is changed for a range covering the three flow regimes (laminar, transient and turbulent). Effects of the number of blades on the flow patterns, pumping rate and power consumption are also studied.

\section{Agitation system}

An agitation system (Fig. 1) comprising an unbaffled and flat-bottomed tank equipped with a V-cut turbine, is chosen to carry out this study. The stirrer is, perhaps, the critical part of this system, since it provides the origin of the kinetic energy and it determines the type of flow, the pumping and the circulation intensity of the fluid; as a result, the agitators are chosen according to the objective pursued the operation [16]. It is not surprising, at this point, that several authors base their thinking on the design and geometry of the mixer $[17,18]$. In our study, we are interested in the effect of the number of blades $(\alpha)$, ranging from two to six blades. The stirrer is placed at the mid-height of a tank having a diameter $D=300 \mathrm{~mm}$. The values: $H / D=1$, $d / D=0.5, h / D=0.1, d_{s} / D=0.05$ are, respectively, the vessel height, the blade diameter, blade height and the shaft diameter. Values of the lengths $a, b$ and $c$ as shown in Fig. 1 are: $a / D=0.033, b / D=0.066$ and $c / D=0.072$.

The working fluid is a solution of CMC (Carboxy Methyl Cellulose) having the following rheological properties: concentration $C=0.04[\mathrm{~g} \mathrm{CMC/g}]$, consistency index $m=0.79\left[\mathrm{~Pa} \mathrm{~s}^{\mathrm{n}}\right]$, behavior index $n=0.83$. This fluid has a shear-thinning behavior modeled by Ostwald's law.

\section{Computational methodology}

The study is achieved via numerical simulation by using the computer tool ICEM CFD to create the computational domain and mesh. Then, the computer software CFX is used to perform calculations.

Mesh tests were achieved as detailed in Table 1. The density of the first mesh, which had about 378,499 elements, was increased by about two times (762,549 elements) and two
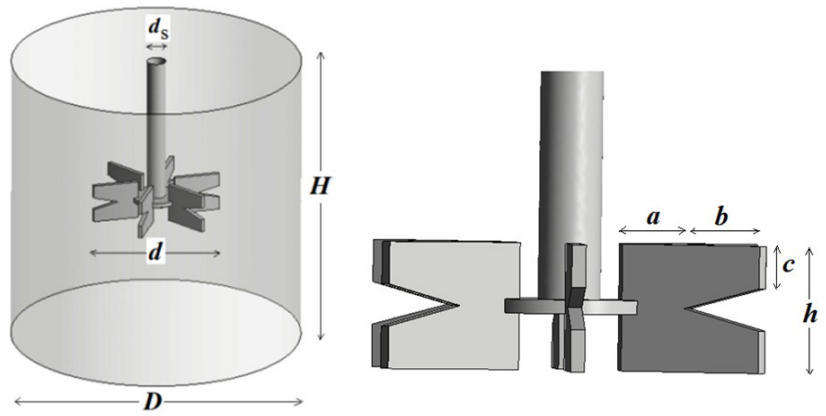

Fig. 1 The geometry of the agitation system
Table 1 Results of the mesh tests

\begin{tabular}{lccc}
\hline & Mesh 1 & Mesh 2 & Mesh 3 \\
\hline Number of grid elements & 378,499 & 762,549 & $1,425,548$ \\
$N q$ & 0.66923 & 0.68013 & 0.68124 \\
$\begin{array}{l}\text { Computational time } \\
\text { [second] }\end{array}$ & 9,984 & 16,548 & 29,854 \\
\hline
\end{tabular}

times again (1,425,548 elements). The velocity at the blade tip and the power consumption were determined for each mesh density. The obtained results showed that the second mesh (762,549 elements) is sufficient since the changes in power number values did not exceed $2 \%$ (Table 1).

Since the tank is unbaffled, the Rotating Reference Frame (RRF) technique was used, i.e. the stirrer is modeled as stationary, and the vessel walls are modeled as rotating zones. The vessel is considered as covered, and the liquid height is kept equal to the vessel height. So, the interaction with air is avoided, and single-phase simulations are performed. For the convection terms, the second-order upwind scheme is selected. A pressure-correction method of the type Semi-Implicit Method for Pressure Linked Equations Consistent (SIMPLEC) is used to perform the pressure-velocity coupling. Further details are available in our previous paper [19].

Calculations were performed in a platform with Core i7 CPU 2.20 GHz and 8.0 GB of RAM. Simulations were considered to be converged when the residual targets of velocities and pressure drop below $10^{-7}$.

\section{Results and discussion}

\subsection{Hydrodynamic}

Fig. 2 shows the flow patterns generated by radial impellers with different numbers of blades $(\alpha)$. The objective of this figure is to illustrate the effect of $\alpha$ on the presence of dead zones near the blade. From this figure, we note that for a two-bladed impeller, there is the presence of a recirculation zone (dead zone) between the end of the blade and the tank wall. When increasing the number of blades, this dead zone decreases until it disappears completely.

\subsection{The pumping rate}

A stirrer rotating in a tank can be considered as a pump: from this viewpoint, it is interesting to know the volume of flow that it provides. By definition, this flow rate $(Q)$ is the amount of liquid that leaves the impeller blades per unit of time, which is given as:

$$
Q=\pi D \int_{0}^{h} V_{r} d z
$$




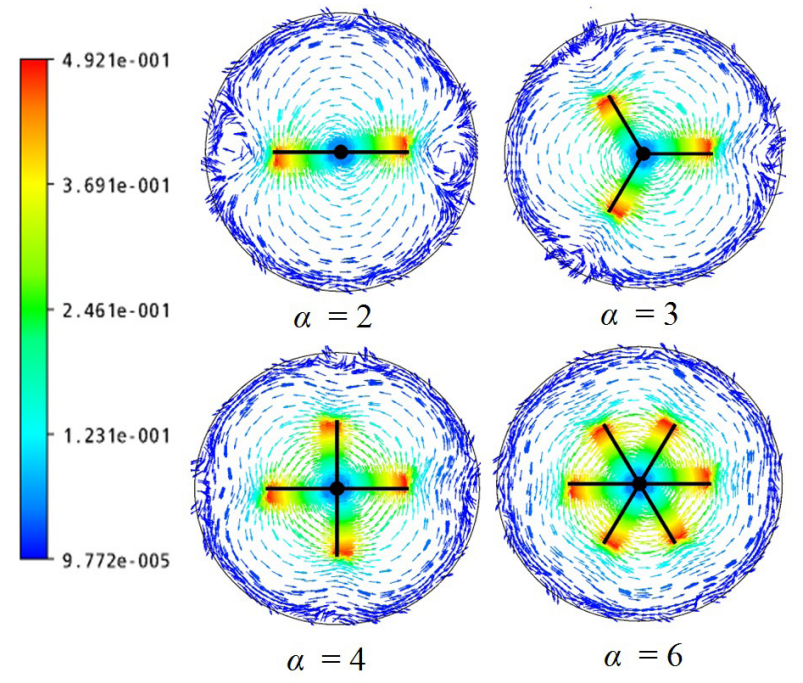

Fig. 2 Effect of the number of blades on the flow patterns for $\operatorname{Re}=50$,

$$
Z^{*}=Z / D=0.5
$$

$V_{r}$ is the radial component of velocity at the blade tip and $Z$ is the position of a flow point on the blade height. $Q$ is referred to as the pumping capacity or the delivery rate of the agitator.

If the total volume of the liquid is divided by this rate, the average time required for a passage through the agitator of all the liquid in the tank is measured. This is why the pumping capacity has proved to be an interesting factor for the correlation of the mixing time [20].

The dimensional analysis shows that $Q$ can be written in the form:

$$
N q=\frac{Q}{N d^{3}}
$$

where $N$ is the impeller rotational speed. $N q$, pumping or discharge coefficient, is a function of the geometry of the stirring system and the physical properties of the liquid.

To validate some predicted results, a geometrical configuration similar to that studied by Mununga et al. [20] was realized, it concerns a turbine with six blades placed at the middle of a tank without baffles. Fig. 3 shows the variation of the pumping rate vs. Reynolds number, the comparison of the two results indicates a satisfactory agreement.

Uhl et al. [21] and Gong et al. [22] reported that the laminar or turbulent agitation gives a molecular diffusion of the fluid particles. Kuncewicz [23] identifies the laminar region for the Reynolds number ( $\mathrm{Re}$ ) less than 70, the fully turbulent flow is for Re greater than $10^{4}$, the region between the two values of Re is considered as transient.

Fig. 4 shows that the discharge rate increases with increasing rotational speed of the stirrer; this is true for the laminar flow. But for the turbulent regime, $\mathrm{Nq}$ is almost constant. Another critical remark is that

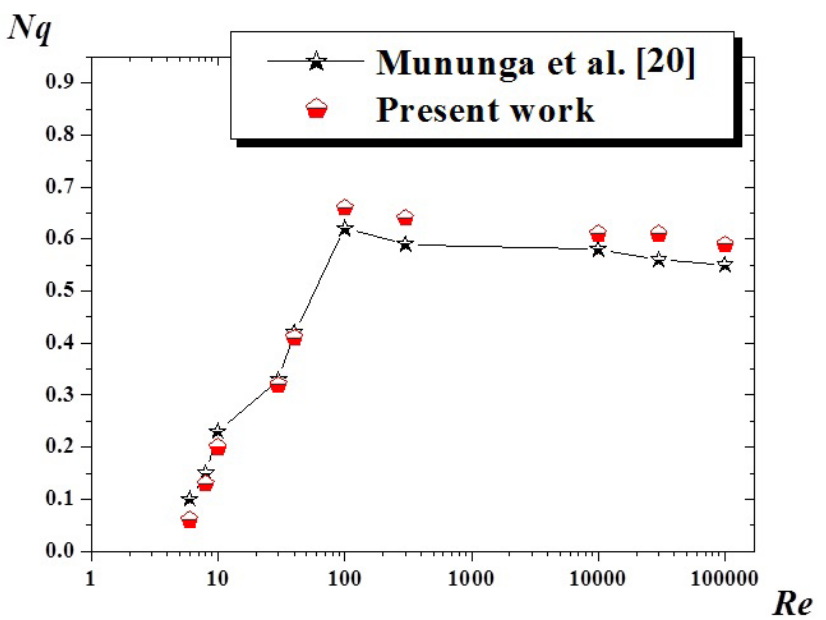

Fig. 3 Flow number for a six-blade turbine (validation of the predicted results)

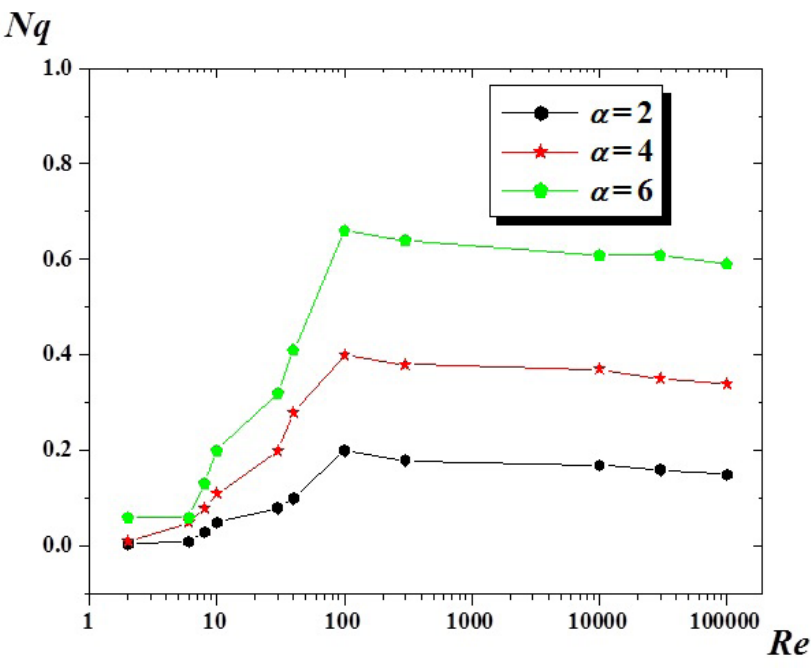

Fig. 4 Flow number vs. Reynolds number for different turbines

the maximum is observed in the transient regime and more precisely at $\mathrm{Re}=200$. The number of blades also influences this parameter; it is the six-bladed turbine that yields the most efficient pumping compared with the other cases considered in this study.

\subsection{Power consumption}

To describe the performance of a mechanically agitated system, it is interesting to determine the power required to complete the operation. The used computer software offers the possibility of evaluating this parameter by integrating the viscous dissipation throughout the volume of the tank.

The viscous dissipation function is expressed as follows:

$Q_{v}=\left(2 \tau_{r r}^{2}+2 \tau_{\theta \theta}^{2}+2 \tau_{z z}^{2}+\tau_{r z}^{2}+\tau_{r \theta}^{2}+\tau_{z \theta}^{2}\right) / \eta^{2}$

where $\eta$ is the viscosity of the fluid. 
The power consumption $(P)$ is given as:

$$
P=\eta \int_{\text {vessel volume }} Q_{v} d v
$$

In dimensionless form, the power number $(N p)$ is defined as:

$$
N p=\frac{P}{\rho N^{3} d^{5}}
$$

where $\rho$ is the fluid density.

The cut in the impeller blade is a new technique to save the energy of impellers in mixing vessel without reducing the product quality or increasing the mixing time [15]. In this section, the effect of impeller blade number and rotational speed on power input is explored.

In Fig. 5, it is observed that the power number is much higher for a turbine with six blades. Furthermore, $N p$ decreases with decreasing number of blades. This remark is valid only for very low Reynolds numbers, i.e. for the deep laminar flow regime. When the flow regime is turbulent, the power number is almost constant, and only a slight difference is observed between the three cases $(\alpha=2,4$, and 6).

\section{Conclusion}

The agitation of a shear-thinning fluid in a cylindrical vessel was explored via numerical simulation. Effects of the impeller blades of a newly designed impeller on the flow patterns, pumping rate and power consumption were investigated. Effect of the impeller rotational speed has also been studied by varying Reynolds number in a range covering the laminar, transitional, and turbulent flow regimes.

The obtained results revealed the formation of a recirculation loop at the blade tip when the number of blades is lower than three. These recirculation loops disappear with the intensification of tangential velocity, which is the result of the increased number of blades.

In the laminar flow regime, the increased Reynolds number yields an increase in the discharge rate and a decrease in power consumption. However, in the turbulent flow regime, $N q$ and $N p$ remain almost constant.

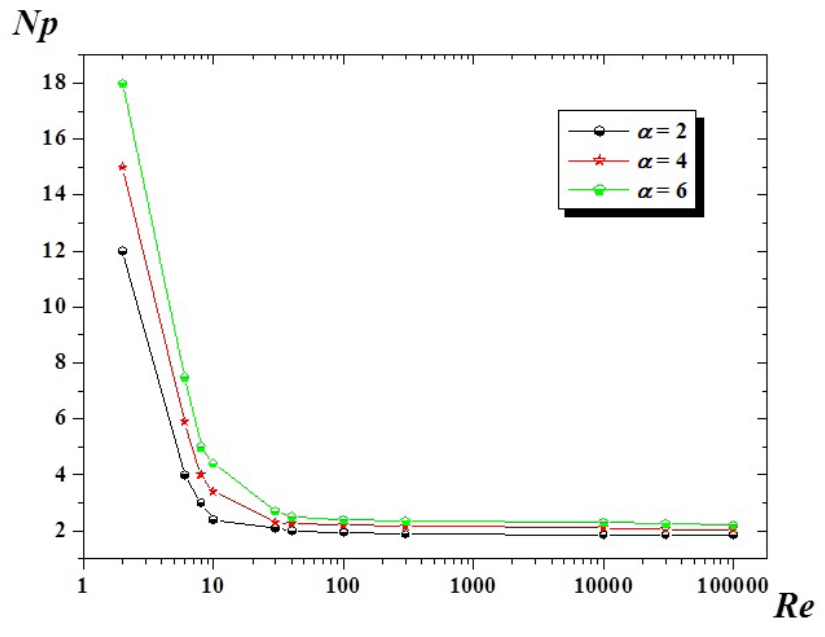

\begin{tabular}{|c|c|}
\hline \multicolumn{2}{|c|}{ Nomenclature } \\
\hline$a, b, c$ & Lengths in the impeller blade (m) \\
\hline$C$ & Concentration of the $\mathrm{CMC}$ solution $(\mathrm{g} \mathrm{CMC} / \mathrm{g})$ \\
\hline$D$ & Vessel diameter (m) \\
\hline$d_{s}$ & Shaft diameter (m) \\
\hline$H$ & Vessel height (m) \\
\hline$h$ & Blade height (m) \\
\hline$m$ & Consistency index $\left(\mathrm{Pa} \mathrm{s}^{\mathrm{n}}\right)$ \\
\hline$n$ & Flow behavior index (dimensionless) \\
\hline$N$ & Impeller rotational speed $\left(\mathrm{s}^{-1}\right)$ \\
\hline$N p$ & Power number (dimensionless) \\
\hline$N q$ & $\begin{array}{l}\text { Pumping or discharge coefficient } \\
\text { (dimensionless) }\end{array}$ \\
\hline$P$ & Power consumption (W) \\
\hline$Q$ & Flow rate $\left(\mathrm{m}^{3} \mathrm{~s}^{-1}\right)$ \\
\hline$Q_{v}$ & Viscous dissipation $\left(\mathrm{s}^{-2}\right)$ \\
\hline$r, \theta, Z$ & $\begin{array}{l}\text { Radial, tangential, and vertical coordinates, } \\
\text { respectively }(\mathrm{m})\end{array}$ \\
\hline $\mathrm{Re}$ & Reynolds number (dimensionless) \\
\hline$V_{r}, V_{\theta}, V_{z}$ & $\begin{array}{l}\text { Radial, tangential, and axial velocities, respec- } \\
\text { tively }\left(\mathrm{m} \mathrm{s}^{-1}\right)\end{array}$ \\
\hline$Z^{*}$ & $\begin{array}{l}\text { Dimensionless vertical coordinate } \\
\text { (dimensionless) }\end{array}$ \\
\hline$\alpha$ & Number of blades (dimensionless) \\
\hline$\eta$ & Apparent viscosity ( $\mathrm{Pa} \mathrm{s}$ ) \\
\hline$\rho$ & Fluid density $\left(\mathrm{kg} \mathrm{m}^{-3}\right)$ \\
\hline$\tau$ & Shear stress $(\mathrm{Pa})$ \\
\hline
\end{tabular}

Fig. 5 Power number vs. Reynolds number

\section{References}

[1] Ameur, H. "Mixing of a Viscoplastic Fluid in Cylindrical Vessels Equipped with Paddle Impellers", ChemistrySelect, 2(35), pp. 11492-11496, 2017. https://doi.org/10.1002/slct.201702459
[2] Ameur, H. "Energy efficiency of different impellers in stirred tank reactors", Energy, 93, pp. 1980-1988, 2015. https://doi.org/10.1016/j.energy.2015.10.084 
[3] Wang, P., Reviol, T., Kluck, S., Würtz, P., Böhle, M. "Mixing of non-Newtonian fluids in a cylindrical stirred vessel equipped with a novel side-entry propeller", Chemical Engineering Science, 190, pp. 384-395, 2018.

https://doi.org/10.1016/j.ces.2018.06.034

[4] Kazemzadeh, A., Ein-Mozaffari, F., Lohi, A., Pakzad, L. "Intensification of mixing of shear-thinning fluids possessing yield stress with the coaxial mixers composed of two different central impellers and an anchor", Chemical Engineering and Processing: Process Intensification, 111, pp. 101-114, 2017.

https://doi.org/10.1016/j.cep.2016.10.019

[5] Ohmura, N., Masuda, H., Wang, S. "Intensification of Mixing Processes with Complex Fluids", Journal of Chemical Engineering of Japan, 51(2), pp. 129-135, 2018.

https://doi.org/10.1252/jcej.17we149

[6] Ashory, M.-R., Talebi, F., Roohi Ghadikolaei, H., Karimpour, M. "An Investigation into Different Power Consumption Parameters of Rushton Turbines: A Computational Survey", Transactions of FAMENA, 41(4), pp. 35-46, 2017.

https://doi.org/10.21278/TOF.41404

[7] Beloudane, M., Bouzit, M., Ameur, H. "Numerical investigation of the turbulent flow generated with a radial Turbine using a converging hollow blade", Polish Journal of Chemical Technology, 20(4), pp. 129-137, 2018.

https://doi.org/10.2478/pjct-2018-0065

[8] Foukrach, M., Ameur, H. "Effect of impeller blade curvature on the hydrodynamics and power consumption in a stirred tank", Chemical Industry \& Chemical Engineering Quarterly, 2020. https://doi.org/10.2298/CICEQ190804003F

[9] Foukrach, M., Ameur, H. "Effect of baffles shape on the flow patterns and power consumption in stirred vessels", SN Applied Sciences, 1, Article number: 1503, 2019. https://doi.org/10.1007/s42452-019-1550-9

[10] Kamla, Y., Ameur, H., Karas, A., Arab, M. I. "Performance of new designed anchor impellers in stirred tanks", Chemical Papers, 74, pp. 779-785, 2020.

https://doi.org/10.1007/s11696-019-00902-X

[11] Foukrach, M., Bouzit, M, Ameur, H., Kamla, Y. "Effect of Agitator's Types on the Hydrodynamic Flow in an Agitated Tank", Chinese Journal of Mechanical Engineering 33, Article number: 37, 2020. https://doi.org/10.1186/s10033-020-00454-2

[12] Rao, D. A., Sivashanmugam, P. "Experimental and CFD simulation studies on power consumption in mixing using energy saving turbine agitator", Journal of Industrial and Engineering Chemistry, 16(1), pp. 157-161, 2010.

https://doi.org/10.1016/j.jiec.2010.01.002
[13] Ameur, H. "Modifications in the Rushton turbine for mixing viscoplastic fluids", Journal of Food Engineering, 233, pp. 117-125, 2018. https://doi.org/10.1016/j.jfoodeng.2018.04.005

[14] Ameur, H. "Some modifications in the Scaba 6SRGT impeller to enhance the mixing characteristics of Hershel-Bulkley fluids", Food and Bioproducts Processing, 117, pp. 302-309, 2019. https://doi.org/10.1016/j.fbp.2019.08.007

[15] Ameur, H., Vial, C. "Modified Scaba 6SRGT impellers for process intensification: Cavern size and energy saving when stirring viscoplastic fluids", Chemical Engineering and Processing - Process Intensification, 148, Article number: 107795, 2020. https://doi.org/10.1016/j.cep.2019.107795

[16] Ameur, H., Kamla, Y., Sahel, D. "Optimization of the Operating and Design Conditions to Reduce the Power Consumption in a Vessel Stirred by a Paddle Impeller", Periodica Polytechnica Mechanical Engineering, 62(4), pp. 312-319, 2018. https://doi.org/10.3311/PPme.12372

[17] Guo, C., Xue, S., Li, W., Qin, H., Guo, J., Zhang, J. "Investigation of power characteristics in a novel cup-shaped-blade mixer", Chemical Engineering and Processing: Process Intensification, 125, pp. 150-162, 2018. https://doi.org/10.1016/j.cep.2018.01.025

[18] Yamamoto, T., Suzuki, A., Komarov, S. V., Ishiwata, Y. "Investigation of impeller design and flow structures in mechanical stirring of molten aluminum", Journal of Materials Processing Technology, 261, pp. 164-172, 2018. https://doi.org/10.1016/j.jmatprotec.2018.06.012

[19] Ameur, H., Ghenaim, A. "Mixing of Complex Fluids in a Cylindrical Tank by a Modified Anchor Impeller", ChemistrySelect, 3(26), pp. 7472-7477, 2018. https://doi.org/10.1002/slct.201801047

[20] Mununga, L., Hourigan, K., Thompson, M. "Numerical Study of the Effect of Blade Sze on Pumping Effectiveness of a Paddle Impeller in an Unbaffled Mixing Vessel", Third International Conference on CFD in Minerals and Process Industries, Melbourne, Australia, 2003, pp. 299-304.

[21] Uhl, V. W., Gray, J. B. "Mixing: Theory and Practice", Vol. 1, Academic Press, New York, NY, USA, 1966.

[22] Gong, H., Huang, F., Li, Z., Gao, Z., Derksen, J. J. "Mechanisms for drawdown of floating particles in a laminar stirred tank flow", Chemical Engineering Journal, 346, pp. 340-350, 2018. https://doi.org/10.1016/j.cej.2018.04.011

[23] Kuncewicz, C. "Three-dimensional model of laminar liquid flow for paddle impellers and flat-blade turbines", Chemical Engineering Science, 47(15-16), pp. 3959-3967, 1992. https://doi.org/10.1016/0009-2509(92)85145-2 